\title{
Organisational Readiness and Software Process Improvement
}

\author{
Mahmood Niazi ${ }^{\mathrm{a}}$, David Wilson ${ }^{\mathrm{b}}$ and Didar Zowghi ${ }^{\mathrm{b}}$ \\ ${ }^{\text {a }}$ School of Computing and Mathematics, Keele University, ST5 5BG, UK \\ mkniazi@cs.keele.ac.uk \\ ${ }^{\mathrm{b}}$ Faculty of Information Technology, University of Technology Sydney, NSW 2007, \\ Australia
}

\begin{abstract}
The Capability Maturity Model Integration (CMMI) is a structured representation of software development processes that can support an organisation's software process improvement (SPI) strategies. However, CMMI and SPI initiatives generally exhibit low levels of adoption and limited success. One of the major reasons for these shortcomings is that many organisations undertake SPI initiatives without knowing whether or not they are ready to undertake them. Our previous research has enabled us to develop a software process improvement readiness model/framework to address this problem.

This paper reports on the implementation of the SPI readiness model in three large-scale case studies. We have found that organisations with higher CMMI levels are more ready for SPI initiatives than organisations with low CMMI levels. We suggest that organisations at higher CMMI levels have developed capabilities that enable them to further leverage SPI than organisations at lower CMMI levels.
\end{abstract}

Keywords: Software Process Improvement, Case Study, Organisational Readiness

\section{Introduction}

Software Process Improvement (SPI) has been a long-standing approach promoted by software engineering researchers, intended to help organisations develop higherquality software more efficiently. Process capability maturity models such as CMM, CMMI (Chrissis et al., 2003) and ISO/IEC 15504 (SPICE) are SPI frameworks for defining and measuring processes and practices that can be used by software developing organisations. However, only a small number of software organisations have successfully adopted SPI. SPI initiatives exhibit low levels of adoption and limited success [1]. Deployment is often not only multi-project, but multi-site and multi-customer and the whole SPI initiative typically requires a long-term approach. It takes significant time to fully implement an SPI initiative [2]. A recent report of the Software Engineering Institute shows the number of months needed in order to move from one maturity level of CMM to the next one [2]: 
- Maturity level 1 to 2 is 22 months

- Maturity level 2 to 3 is 19 months

- Maturity level 3 to 4 is 25 months

- Maturity level 4 to 5 is 13 months

Such time frames mean that the SPI approach is often considered an expensive challenge for many organizations [1] as they need to commit significant resources over an extensive period of time. Even organisations who are willing to commit the resources and time do not always achieve their desired results. The failure rate of SPI initiatives is very high, estimated as $70 \%$ [3; 4]. The significant investment and limited success are reasons for many organisations being reluctant to embark on a long path of systematic process improvement.

In order to improve the SPI implementation process, in our previous research, we have developed a SPI implementation readiness model [5]. The objective of the SPI readiness model is to assist organisations in assessing and improving their SPI implementation readiness. In this paper we report on our evaluation of the readiness model in three large scale case studies. The objective of this evaluation is to further improve the readiness model and to observe the correlation between organisation readiness and SPI maturity.

In this paper we have addressed the following research question:

RQ: Are organisations in higher CMM(I) levels more ready for SPI implementation than organisations in lower CMM(I) levels?

This paper is organised as follows. Section 2 describes the background. Section 3 describes the research design. In Section 4 findings are presented and analysed. Discussion is provided in Section 5. In Section 6 case study validity is discussed. Section 7 provides the conclusion.

\section{Background}

Despite the importance of the SPI implementation process, little empirical research has been carried out on developing ways in which to effectively implement SPI programmes $[1 ; 6]$. Much attention has been paid to developing standards and models for SPI. Also, organisations typically adopt ad hoc methods instead of standard, systematic and rigorous methods in order to implement SPI initiatives [7]. This risk can lead organisations to a chaotic situation with no standard for SPI implementation practices. In the appraisal of SPI models, e.g. CMMI, the software process maturity of the organisations is assessed. Little attention, however, has been paid to assess the SPI implementation maturity/ readiness of the organisations. The assessment of SPI implementation maturity/ readiness can help organisations in successfully implementing SPI initiatives. This is because the readiness of the organisations for successfully implementing SPI initiatives could be judged through this SPI implementation maturity. We have focused on these issues and developed a SPI readiness model (as shown in Figure 1) in order to assess the SPI implementation maturity/ readiness of the organisations [8; 9]. The CMMI perspective [10] and the findings from our previous empirical study [11] were used in the design of the SPI readiness model. The SPI readiness model has four SPI implementation maturity/ 
readiness levels abstracted from CMMI. These maturity levels contain different critical success factors (CSFs) [11] and critical barriers (CBs) [12] identified through the literature and interviews. Under each factor, different practices have been designed that guide how to assess and implement each factor.

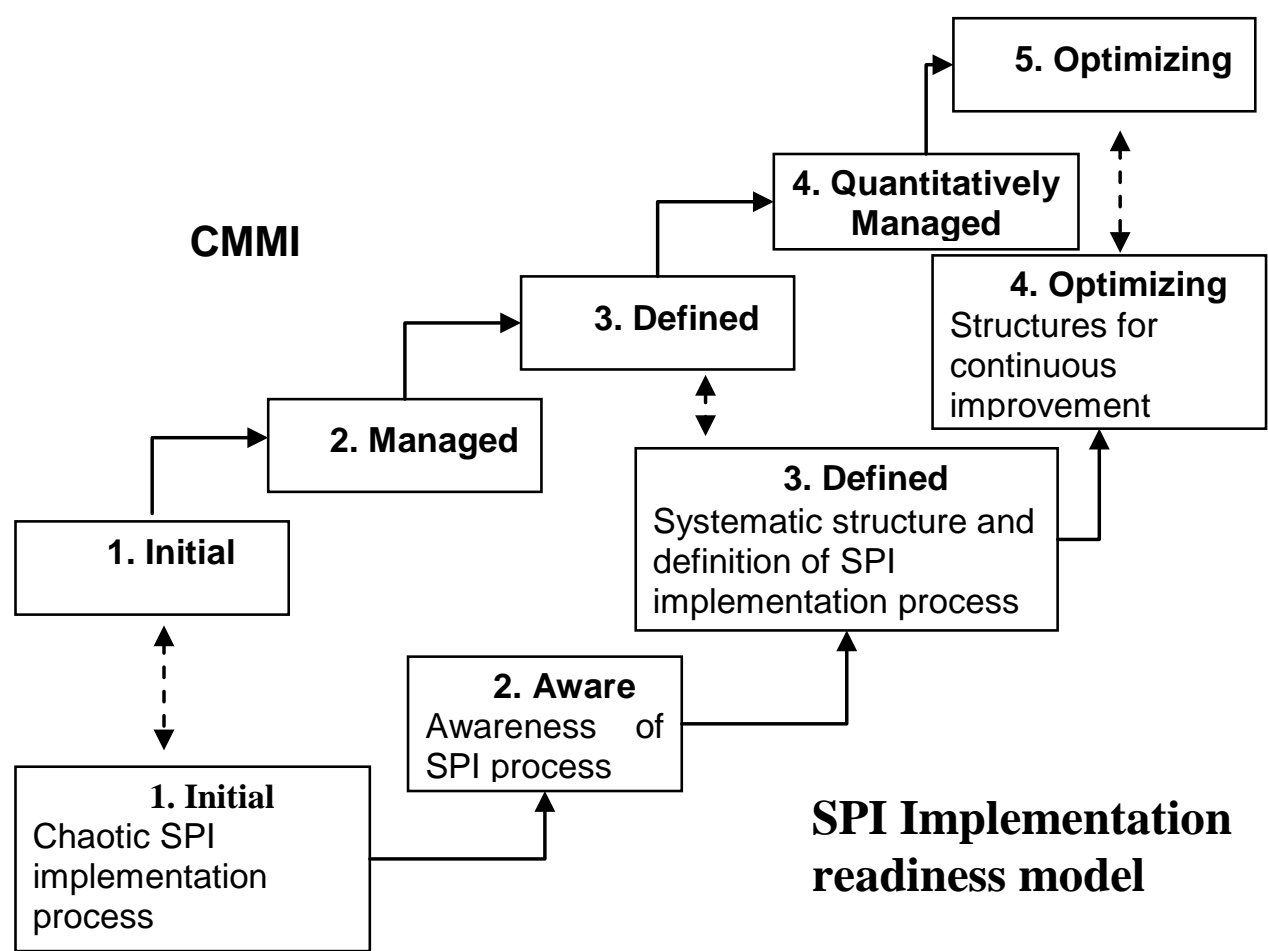

Figure 1 SPI implementation readiness model [8]

\section{Study Design}

The case study method was used because this method is said to be powerful for evaluation and can provide sufficient information in the real software industry environment [13]. The case study also provides valuable insights for problem solving, evaluation and strategy [14]. Since the SPI readiness model is more applicable to a real software industry environment, the case study research method is believed to be a more appropriate method for this situation.

Real life case studies were necessary because they: 
- Showed that the SPI readiness model is suitable or will fit in the real world environment.

- Highlighted areas where the SPI readiness model needs improvement.

- Showed the practicality and usability of the SPI readiness model use.

To provide more confidence in this study, three separate case studies were conducted at three different organisations. Organisations were selected for case studies because they provided especially rich descriptions of their SPI efforts and because they agreed to release the case studies results.

Initially, we talked to each participant face-to-face, explained what the case study was about and handed out a hard copy of the SPI readiness model. The participants also contacted us through emails to solicit more information about the use of the SPI readiness model. One participant from each organisation, who was the key member of SPI team, was involved in each case study. The key participant communicated with us through email and face-to-face discussion for one month in order to get a thorough understanding of the SPI readiness model. Different components of the SPI readiness model were explained and participants were encouraged to use this model independently.

In each case study, a participant used the SPI readiness model and assessed the SPI implementation readiness of his/her organisation independently without any suggestion or help from the researchers. At the end of each case study, an interview was conducted with the participant in order to provide feedback about the SPI readiness model. A questionnaire (available from the authors) was used as a means to structure this feedback session. This questionnaire is divided into four parts: demographic, ease of learning, user satisfaction and structure of the SPI readiness model. Each feedback session was an informal discussion and the questionnaire was filled out by each participant. Each questionnaire was analysed qualitatively.

\section{Findings}

The three organisations in our case study are called "Organisation A", "Organisation $\mathrm{B}$ " and "Organisation C". The assessment process for SPI implementation readiness is described in [8].

\subsection{SPI implementation readiness of organisation A}

Organisation $\mathrm{A}$ is an international organisation that provides consultancy and information technology services to both the private and public sector, employing 10,000 professionals in Asia Pacific, Canada, Europe and United Sates. The main purpose of the organisation is to enhance the efficiency and effectiveness of the Information Systems prevailing in the public and private sectors by applying relevant state-of-the-art technologies related to computer software, hardware and data communication.

The following are some of the major areas in which Organisation A can provide services to its clients: 
- E-Business

- Enterprise Consulting

- Technology Consulting

- Solution Delivery

- Application Portfolio Management/ Outsourcing

- Project Management

An SPI initiative was initiated seven years ago in Organisation A. The reasons for initiating the SPI programme were:

- To reduce software development cost

- To improve management visibility in software development

- To increase productivity

- To improve the quality of the software developed

- To meet customer requirements

The SPI programme was initiated by the research division of Organisation A. The research division has developed a standard methodology for software development. During the development of this methodology special attention was given to the requirements of the ISO 9001 standard and the CMM model. Organisation A is ISO 9001 certified and is currently assessed at CMM level 3.

The assessment results of Organisation A are summarised in Table 1. The key points of this assessment are as follows:

- It is clear that Organisation A stands at Level-1 'Initial' of the SPI readiness model because two factors of Level-2 'Aware' are not fully implemented in Organisation A. In order to achieve any maturity level it is important that all the CSFs and CBs that belong to that maturity level should have been fully implemented. Table 1 shows that in order to achieve Level-2 'Aware' the Organisation A needs to improve two factors, i.e. senior management commitment and staff involvement. Similarly, in order to achieve Level-3 'Defined' the Organisation A needs to improve 3 factors, i.e. Creating process action teams, Staff time and resources and Time pressure.

- It shows that Organisation A has well defined training and SPI awareness programmes.

- SPI activities have been assigned to experienced staff members.

- It is clear that a defined SPI implementation methodology is in use and Organisation A managed to avoid organizational politics. The defined SPI implementation methodology could be the reason that this organisation was assessed in CMM Level-3.

- Organisation A has established some processes in order to review the implementation processes

Organisation A is a relatively high maturity organisation with CMM Level-3. It is surprising to see that Organisation A has not successfully implemented these factors such as 'senior management commitment', 'staff involvement', 'creating process action teams', 'staff time and resources' and 'time pressure'. As these factors are weak in organisation A therefore this organisation stands in Level-1 'Initial' of SPI readiness model. 
Table 1. SPI implementation readiness of organisation A

\begin{tabular}{lll}
\hline Readiness Level & Critical success factors and barriers & Status \\
\hline Level-2 Aware & Senior management commitment & weak \\
& Training and mentoring & strong \\
& Staff involvement & weak \\
& Awareness of SPI & strong \\
& Lack of support & strong \\
Level-3 Defined & Creating process action teams & weak \\
& Experienced staff & strong \\
& Staff time and resources & weak \\
& Defined SPI implementation methodology & strong \\
& Time pressure & weak \\
& Organizational politics & strong \\
Level-4 Optimising & Reviews & strong \\
\hline
\end{tabular}

\subsection{SPI implementation readiness of organisation B}

Organisation B is an international organisation that provides consultancy and information technology services to both the private and public sector, employing more than 2000 professionals in Australia and worldwide. The core business of the organisation is to provide services in software development, system integration, business innovation and business process improvement.

The following are some of the major areas in which Organisation B can provide services to its clients:

- Business and IT services

- Business consulting services

- Infrastructure services

- Financing

- E-Business

- Project Management

The organisation delivers complex software systems to a number of clients. The SPI programme was initiated five years ago in Organisation B. The main reasons for initiating the SPI programmes were to:

- Reduce development cost and time to market

- Increase productivity and quality of the product

Organisation B adopted a CMM model for its SPI programme. According to self assessment results, the organization's process maturity was found to be in CMM 
Level 1. The process teams undertook different SPI actions in order to achieve level 2, i.e. working on requirements management, software project planning and software quality assurance etc. Using CMM-based assessment in 2001, the process maturity was found to be in CMM level 2 with traces of Level 3. Now organisation B is working to achieve level 3.

The SPI implementation readiness assessment results of Organisation B are summarised in Table 2:

- It is clear that Organisation B stands at Level-1 'Initial' because four factors of Level-2 'Aware' are not fully implemented in the Organisation B. Table 2 shows that in order to achieve Level-2 'Aware' the Organisation B needs to improve four factors, i.e. training and mentoring, staff involvement, awareness of SPI and lack of support.

- In order to achieve Level-3 'Defined' and Level-4 'Optimising' the Organisation B needs to improve five factors, i.e. creating process action teams, experienced staff, staff time and resources, time pressure and reviews.

- It also shows that the Organisation B has adequate senior management support for SPI programmes.

- Table 2 shows that a defined SPI implementation methodology is in use and Organisation B managed to avoid organisational politics.

Table 2. SPI implementation readiness of organisation B

\begin{tabular}{lll}
\hline Readiness Level & Critical success factors and barriers & Status \\
\hline Level-2 Aware & Senior management commitment & strong \\
& Training and mentoring & weak \\
& Staff involvement & weak \\
& Awareness of SPI & weak \\
& Lack of support & weak \\
Level-3 Defined & Creating process action teams & weak \\
& Experienced staff & weak \\
& Staff time and resources & weak \\
& Defined SPI implementation methodology & strong \\
& Time pressure & Weak \\
& Organizational politics & Strong \\
Level-4 Optimising & Reviews & Weak \\
\hline
\end{tabular}




\subsection{SPI implementation readiness of organisation C}

Organisation C provides telecommunication services and employs more than 2000 professionals in Australia and worldwide. The core business of the organisation is to provide cutting-edge communications, information and entertainment services. The organisation provides a broad range of communications services including mobile, national and long distance services, local telephony, international telephony, business network services, Internet and satellite services and subscription television.

The SPI programme was initiated in Organisation $C$ three years ago. The reasons for initiating the SPI programmes were:

- To reduce software development cost

- To reduce time-to-market

- To increase productivity

- To improve the quality of the software developed

- To automate the production of relevant development documentation

In 2002 this Organisation C was assessed at CMM level 2. The SPI implementation readiness assessment results of Organisation B are summarised in Table 3:

Table 3. SPI implementation readiness of organisation C

\begin{tabular}{lll}
\hline Readiness Level & Critical success factors and barriers & Status \\
\hline Level-2 Aware & Senior management commitment & Weak \\
& Training and mentoring & Weak \\
& Staff involvement & Strong \\
& Awareness of SPI & Weak \\
& Lack of support & Weak \\
Level-3 Defined & Creating process action teams & Strong \\
& Experienced staff & Weak \\
& Staff time and resources & Weak \\
& Defined SPI implementation methodology & Strong \\
& Time pressure & Weak \\
& Organizational politics & Weak \\
& Reviews & Weak \\
\hline
\end{tabular}

- It is clear that Organisation C stands in Level-1 'Initial' because four factors of Level-2 'aware' are not fully implemented in the Organisation C. 
- In order to achieve Level-3 'Defined' and Level-4 'Optimising' the Organisation $\mathrm{C}$ needs to improve five factors, i.e. experienced staff, staff time and resources, time pressure, organizational politics and reviews.

- It also shows that the Organisation C has experienced staff for SPI programmes.

- A defined SPI implementation methodology is in use and Organisation C has created teams for SPI activities.

\section{Discussion}

The CMMI framework is structured into five maturity levels ranging from level 1 to 5. Each maturity level expresses a different state of software development maturity in an organisation. Level-1 corresponds to the lowest state of software development maturity while level-5 corresponds to the highest state of software development maturity. We argue that higher levels of CMMI (level 3 and above) indicate that the organisation has well defined processes for the implementation of SPI initiatives. This is because the organisation has successfully implemented CMMI. While lower levels of CMMI (level 2 and below) indicate that the organisation does not have well defined processes for the implementation of SPI initiatives. This is because the organisation is struggling to successfully implement CMMI. Keeping in view these points, the organisations in higher CMMI levels should have less implementation issues than organisations in lower CMMI levels.

In order to address above points our research question was:

RQ: Are organisations in higher CMM(I) levels more ready for SPI implementation than organisations in lower CMM(I) levels?

In order to address this research question, it is important to compare the results of the three case studies. As discussed earlier Organisation A is at CMM Level-3 and Organisations B and C are at CMM Level-2 respectively. The results of the three case studies are summarised into Table 4.

As discussed in Section 4 all organisation were assessed at Level-1 Aware of SPI implementation readiness model. However, by looking at weak implementation factors we have noticed the following differences:

- Organisation A has only two weak factors in level-2, while Organisations B and $\mathrm{C}$ have four weak factors in Level-2.

- For Level-3, Organisation A has three weak factors while Organisations B and $\mathrm{C}$ have four weak factors.

- Table 4 shows that Organisation A has successfully implemented more implementation factors than Organisations B and C. This also shows that Organisation A has less weak implementation factors (i.e. five) than Organisations B and C (i.e. nine).

- It shows that $78 \%$ (i.e. seven factors) of the weak factors are common between CMM Level-2 organisations B and C.

These findings have confirmed our research question that organisations with higher CMMI levels are more ready than organisations with low CMMI levels. 
Table 4. Summary of results of organisations A, B and C

\begin{tabular}{|c|c|c|c|}
\hline Assessment issue & $\begin{array}{l}\text { Organisation A } \\
\text { (CMM Level-3) }\end{array}$ & $\begin{array}{l}\text { Organisation B } \\
\text { (CMM Level-2) }\end{array}$ & $\begin{array}{l}\text { Organisation C } \\
\text { (CMM Level-2) }\end{array}$ \\
\hline $\begin{array}{l}\text { Weak } \\
\text { implementation } \\
\text { factors in SPI } \\
\text { readiness model } \\
\text { Level-2 'Aware' }\end{array}$ & $\begin{array}{l}\text { - Senior management } \\
\text { commitment } \\
\text { - Staff involvement }\end{array}$ & $\begin{array}{ll}\text { - } & \text { Awareness of } \\
& \text { SPI } \\
\text { - } & \text { Lack of support } \\
\text { - } & \begin{array}{l}\text { Staff } \\
\text { involvement }\end{array} \\
\text { - } & \begin{array}{l}\text { Training and } \\
\text { mentoring }\end{array}\end{array}$ & $\begin{array}{ll}\text { - } & \text { Awareness of SPI } \\
\text { - } & \text { Lack of support } \\
\text { - } & \text { Senior } \\
\text { management } \\
\text { commitment } \\
\text { - } & \begin{array}{l}\text { Training and } \\
\text { mentoring }\end{array}\end{array}$ \\
\hline $\begin{array}{l}\text { Weak } \\
\text { implementation } \\
\text { factors in SPI } \\
\text { readiness model } \\
\text { Level-3 'Defined' }\end{array}$ & $\begin{array}{l}\text { - Creating process } \\
\text { action teams } \\
\text { - Staff time and } \\
\text { resources } \\
\text { - Time pressure }\end{array}$ & $\begin{array}{ll}\text { - } & \text { Creating } \\
& \text { process action } \\
\text { teams } \\
\text { - } & \begin{array}{l}\text { Experienced } \\
\text { staff }\end{array} \\
\text { - } & \begin{array}{l}\text { Staff time and } \\
\text { resources }\end{array} \\
\text { - } & \text { Time pressure }\end{array}$ & $\begin{array}{ll}\text { - } & \text { Experienced staff } \\
\text { - } & \text { Staff time and } \\
\text { resources } \\
\text { - } & \text { Time pressure } \\
\text { - } & \text { Organizational } \\
\text { politics }\end{array}$ \\
\hline $\begin{array}{l}\text { Weak } \\
\text { implementation } \\
\text { factors in SPI } \\
\text { readiness model } \\
\text { Level-4 } \\
\text { 'Optimising' }\end{array}$ & - Nil & - $\quad$ Reviews & - Reviews \\
\hline $\begin{array}{l}\text { Total Weak } \\
\text { implementation } \\
\text { factors }\end{array}$ & 5 & 9 & 9 \\
\hline
\end{tabular}

Comparison of weak factors of the three organisations provides evidence that there are some clear similarities and differences between the findings of the three data sets. The factors 'time pressure' and 'staff time and resources' are common among three organisations. This shows that organisations both at lower and higher levels of CMMI need to improve these two common factors. In the literature different studies have discussed 'time pressure' and 'staff time and resources' as barriers for SPI implementation. For example, Baddoo and Hall [15] present empirical findings analysing what de-motivates UK practitioners in SPI. The authors have separated senior managers, project managers and developers into separate focus groups. The authors state that all the groups of practitioners have cited time pressure as a demotivator for SPI, i.e. $62 \%$ of developers cited, $44 \%$ of project managers cited and $58 \%$ of senior managers cited. In the study of Goldenson and Herbsleb [6] "almost three-quarters (72\%) report that process improvement has often suffered due to time 
and resource limitations”. Paulish and Carleton [16] also describe case studies for SPI measurement and illustrate time restriction as one of the SPI implementation problem.

Table 4 also shows factors that are common between organisations of lower CMMI level (i.e. CMM level 2). For example, the organisations at lower CMM level are having problems of 'awareness of SPI', 'experienced staff', 'lack of support', 'training and mentoring' and 'reviews'. These factors need to be addressed in order to successfully implement SPI initiatives.

\section{Case Study Validity}

Two types of threats to case study validity are relevant to this study: construct validity and external validity [17]. Construct validity is concerned with whether or not the measurement scales represent the attributes being measured. The attributes are taken from a substantial body of previous research [18; 19] and further studies conducted by one of the authors [8]. The responses from the post case study questionnaire show that all the attributes considered were relevant to their workspace. Also, all participants agreed with the assessment results.

External validity is concerned with the generalisation of the results to other environments than the one in which the initial study was conducted [20]. Since three case studies were conducted, it is hard to justify the external validity at this stage. However, since SPI readiness model's evaluation is currently limited to only the three organisations reported in this study, generalisation to whole software industry should be considered with extreme caution.

\section{Conclusion}

In this research a case study method was chosen because the SPI implementation readiness model is more applicable to the real software industry environment. Three separate case studies were conducted at three different companies. The results of the case studies show that the SPI implementation readiness model is not only significant in the theoretical work but also significant in the real world environment as each of the three companies was able to successfully use the SPI implementation readiness model to assess their SPI implementation readiness. The participants have noticed the SPI implementation issues that the SPI implementation readiness model has identified for their companies and they were agreed with those issues.

We have found that organisations with higher CMMI levels were more ready for SPI initiatives than organisations with low CMMI levels. We suggest that readiness for SPI is directly associated with organisations' software development maturity. We have also found some clear similarities and differences between the findings of three case studies. For successful SPI initiatives, the organisations both at lower and higher levels of CMMI need to facilitate their staff members from time pressure and need to allocate required resources for SPI activities. We found that the organisations at lower CMM level are having problems of 'awareness of SPI', 
'experienced staff', 'lack of support', 'training and mentoring' and 'reviews'. These factors need to be addressed in order to successfully implement SPI initiatives.

\section{References}

1 Leung, H.: Slow change of information system development practice, Software quality journal 8 (3). (1999) 197-210.

2 SEI: Process Maturity Profile. Software Engineering Institute Carnegie Mellon University, (2004).

3 SEI: Process maturity profile of the software community. Software Engineering Institute, (2002).

$4 \quad$ Ngwenyama, O. and Nielsen, P., A.: Competing values in software process improvement: An assumption analysis of CMM from an organizational culture perspective, IEEE Transactions on Software Engineering 50 (2003) 100-112.

5 Niazi, M. and Wilson, D.: A Maturity Model for the Implementation of Software Process Improvement. International Conference on Software Engineering Research and Practice (SERP03), Las Vegas, USA. (2003) 650-655.

6 Goldenson, D. R. and Herbsleb, J. D.: After the appraisal: A systematic survey of Process Improvement, Its benefits, And Factors That Influence Success. SEI, CMU/SEI-95-TR-009, Software Engineering Institute, USA (1995).

7 Zahran, S.: Software process improvement - practical guidelines for business success. Addison-Wesley.(1998).

8 Niazi, M., Wilson, D. and Zowghi, D.: A Maturity Model for the Implementation of Software Process Improvement: An empirical study, Journal of Systems and Software 74 (2). (2005) 155-172.

9 Niazi, M. and Wilson, D.: A Maturity Model for the Implementation of Software Process Improvement. International Conference on Software Engineering Research and Practice (SERP03). (2003) 650-655.

10 SEI: Capability Maturity Model ${ }^{\circledR}$ Integration (CMMISM), Version 1.1. SEI, CMU/SEI-2002-TR-029, Software Engineering Institute, USA (2002).

11 Niazi, M., Wilson, D. and Zowghi, D.: Critical Success Factors for Software Process Improvement: An Empirical Study, Software Process Improvement and Practice Journal 11 (2). (2006) 193-211.

12 Niazi, M., Wilson, D. and Zowghi, D.: Critical Barriers for SPI Implementation: An empirical study. IASTED International Conference on Software Engineering (SE 2004). Austria (2004) 389-395.

13 Yin, R. K.: Applications of Case Study Research. Sage Publications.(1993).

14 Cooper, D. and Schindler, P.: Business research methods, seventh edition. McGraw-Hill.(2001).

15 Baddoo, N. and Hall, T.: De-Motivators of software process improvement: An analysis of practitioner's views, Journal of Systems and Software 66 (1). (2003) 23-33.

16 Paulish, D. and Carleton, A.: Case studies of software process improvement measurement, IEEE Computer 27 (9). (1994) 50-59. 
17 Briand, L., Wust, J. and Lounis, H.: Replicated Case Studies for Investigating Quality Factors in Object Oriented Designs, Empirical Software Engineering 6 (1). (2001) 11-58.

18 Daskalantonakis, M. K.: Achieving higher SEI levels, IEEE Software 11 (4). (1994) 17-24.

19 Beecham, S., Hall, T. and Rainer, A.: Building a requirements process improvement model. Department of Computer Science, University of Hertfordshire, Technical report No: 378 (2003).

20 Regnell, B., Runeson, P. and Thelin, T.: Are the Perspectives Really Different-Further Experimentation on Scenario-Based Reading of Requirements, Empirical Software Engineering 5 (4). (2000) 331-356. 